\title{
Word Order of Noun and Verb Phrases in Contemporary Persian and English Poems
}

\author{
Saloome Rostampour \\ Assistant Professor, Persian Language \& Literature Department, Islamic Azad University (IAU), \\ Eslamshahr Branch
}

\begin{abstract}
Literature is a system of semantic markerswhich convey emotions as well. Sentences in literary texts, particularly poetic ones, are not merely a medium to convey a message. In literary language, there is not a one to one correspondence between words and their meaning. That is in literary texts, the words and consequently sentences do not have their common dictionary meaning. Rather, in many cases, they include the writer's or poet's intended meaning. For writers and poets, words are not simply means of conveying a message, but a scheme to create beauty and novel innovations. The poets to make more impression on their addressees usually create uncommon sentences in the language. To express their feelings and thoughts, they invert the poem's internal word order or sort out the structural system of their poetic sentences counter to standard language. By creating "marked" words or sentences, they actually seek to communicate their audience artistically and innovatively. "Sentence" is the poets' main instrument that according to traditional grammar's definition consists of two parts: subject and predicate. However, in modern linguistics "sentence" is a set of noun and verb phrases that are joined together as a harmonious whole. Each of noun or verb phrases has a unique structure so that their internal order cannot be changed; however, poets make their utterance poetic by inverting these groups to create greater influence.
\end{abstract}

By using "content analysis" method, an attempt is made in this article to analyze the internal orders of noun and verb phrases in contemporary poems.

Keywords: Universal Grammar, Government and Binding Theory, Noun Phrase, Verb Phrase

\section{INTRODUCTION}

Language is an integrated coherent system wherein various units, according to a specific rule and relation to other units, are manifested in given positions. The largest linguistic unit is called "text". Text is a set of meaningful elements in a single structure designed to convey "message" of the speaker to the audience. The meaningful elements of the text are called "sentences" which are the largest grammatical units. Based on traditional grammar, "a word or a group of words that conveys a complete message to the recipient is called a sentence" (Natel Khanlari, 1988: 10).In accordance with modern linguistics, a "sentence" consists of several groups, i.e. "sentence is a language unit consisting of one or more groups" (Vahidian Kamyar, 2008: 9). In other words, a sentence is the result of groups' combination. "By group the structural classification of wordsis meant, i.e. sentences have a group structure" (Cook and Newson, 2011: 47). Aside from being a mere linear order of words, a "sentence" is defined on the basis of the groups within it. There is a semantic relationship among these groups which are divided into two major categories: "noun phrases" and "verb phrases". This classification is "similar to traditional partition of the sentence into a subject and a predicate" (Nematzadeh, 1997: 1). In this way, "a sentence is composed of some groups which are joined together and generate an integrated whole" (Cook and Newson, 2011: 49).

This study is mainly aimed at comparing word order in "noun" and "verb" phrases in Persian and English languages in order to characterize how they are used in contemporary poems of these two languages.

\section{LITERATURE REVIEW}

Every simple sentence has only one "verb phrase"; however, it can have one or more "noun phrase". One of Chomsky's first innovations was representing a sentence structure with a linear diagram as S $\rightarrow$ NP VP that is meant "a sentence is composed of a noun phrase and a verb phrase" (ibid.). In this diagram, the conventional names of NP and VP are used for a noun and a verb phrase, respectively. However, in the above mentioned diagram a verb phrase (VP) consists of a verb and a noun phrase $(\mathrm{V} \rightarrow \mathrm{V} \mathrm{NP})$. According to Meshkatod-Dini, a noun phrase "is a syntactic unit consisted of one or more words which has a noun as its main or head word" (2001: 137). A noun phrase usually plays a single syntactic function in the sentence. For example, in sentence "Our neighbor's eldest son is an office worker", the noun phrase "our neighbor's eldest son" is the subject made up some words.

According to Chomsky's Universal Grammar (UG), every language contains some parameters which are specific to that language. In other words, every language besides universal principles has some parameters that differ among languages. "There aretwo main types of grammatical universals in languages. First, the universals called principles that are common to all languages. Second, the grammatical structures called parameters which are not as universal as principles" (Rezaee, 2011: 36). Based on the universal principles and parameters in any language a theory called "Government and Binding" (GB) has been built. GB Theory assumes that a portion of the grammar of any particular language is common to all languages, and is therefore part of Universal Grammar. The parameters of each language affect the principles which are common to all languages and limit their function. For instance, both noun and verb phrases have universal structures, that is all phrases in all languages consist of a head and some dependents. The "head" is the word which is explained by other words. These words 
that add details or clarify the "head" are called "dependents". For instance, the head of "that two porcelain cups" noun phrase is "cup" and other words are its dependents.

According to the parameters of grammatical structures and the position of "head" in a noun phrase, languages fall into two basic groups: "head-initial" and "head-final". The "head" in "head-initial" languages and "head-final" ones appears at the beginning and end of the phrase, respectively. However, in different languages the position of head cannot be specified with certainty. For example, in English "head" has an initial position. So in noun phrase "The boy", "boy" is the head word. In this way, "open" and "by" are the heads of verb phrase "open the door" and prepositional phrase "by the postman", respectively. In "head-final" languages, the head follows its dependents and appears at the end of phrase, e.g. in Persian the "head" of a verb phrase comes last in its phrase and after all dependents. For instance, "aghaz kard" (began) is a verb phrase. The word "kard" (did it) is its head which has come at the end of phrase. In Persian head position in a noun phrase has a unique behavior, for it can appear at the beginning, e.g. "gol-e Mina" (daisy flower); in the middle, e.g. "hamey-e doostan-e oo" (all of his/her friends); or at the end, e.g. "ba in daneshjoo" (with this student). As a result Dehdari (2007), based on a study on the word order typology of Persian, suggests that Persian is a split-headed language. By investigating head-dependent relations, he concludes "all of head-final relations, either main or auxiliary verbs are considered as heads. Then, based on structural categories, he proposes a split-headed analysis of Persian and provides evidence suggesting that lower predicate structures are head-final, while higher structures are head-initial" (Qorbanpour, 2015: 131).

In another study on head position in Persian, Rezaee (2011) while reviewing the three common views in this regard, namely the issue of head-initiality, head-finality, and split-headedness in Persian language, has pointed out the strong and weak points of them. He, by examination of diachronic evidences within a typological framework, argues that considering Persian as a head-initial language is a more justifiable and tangible analysis in comparison with two other viewpoints. So, in his view the current non-uniformity on head position in different syntactic phrases in Persian must be attributed to a cycle of continuous, but very long-term diachronic changes towards a totally head-initial language (ibid: 132).

The Sequence of words in poetic contexts happens in a variety of fashions. Sometimes, the poet tries to make his utterance especial through novel syntagm of words and sometimes attempts to construct special noun and verb phrases for his/her poems by reordering or rearranging of the words within them in order to create highly impressive utterance for his/her audience. Considering the points given above, the main question in this research is how contemporary poets in Persian and English create special noun or verb phrases for their poems and through what poetic devices use them in their poems? Moreover, is it possible to study various styles of contemporary poets according to their use of particular kind of noun or verb phrases?

\section{METHODOLOGY}

This research has been conducted using a library-based method, so its data has been gathered from relevant sources and then analyzed on the basis of Chomsky's "Government and Binding Theory". The data include examples from works of some of the poets of Persian and English languages.

\section{QUALITATIVE DATA ANALYSIS}

The main body of this research article includes the analysis of the works of contemporary Persian and English poets. Firstly, the word order of noun and verb phrases in both languages is briefly explained. Then some poetry examples for each of the mentioned aspects are provided.

The head position in a noun phrase depends on the word order in each language. For instance, in Persian, the word order is "noun-adjective" (NA); while it is "adjective-noun" (AN) in English, like in "in ketab-e mohemm"(this important book). The head in both phrases is "ketab"(book), but its position is different in the two languages. There is a noticeable difference between the two languages concerning the head position within a "noun phrase". In Persian noun phrases, the definite or indefinite dependents of the head can be omitted, i.e. in the example above one can use "ketab-e mohemm" (important book) in "Persian", but this cannot be done in "English". In other words, one cannot use "important book" alone, rather one of the articles "the" or "a/an" has to be used before the "head". This feature causes an important difference in the two languages when it comes to poetry, e.g. in the following segment, the phrase "dar dahan-e sobh" (in the morning mouth) has no distinctive feature:

"Be-nafasmishodsiyahidardahan-e sobh/ Bad par mirikhtrooy-e dasht-e baz-e daman-e Alborz"' (Kasra'i, 2014: 61)

But in English poems, a distinctive feature has to be specified for each noun phrase. Like in:

The coal-house door, once I looked up /Through the brunt wind that dented the balls of my eyes" (Ted Hughes)

A verb determines the number of noun phrases in the sentence. Each verb can be either obligatory or optional associated to one or several noun phrases. For instance, in this sentence: "I have given a book to him in the park", the verb "have given" controls three noun phrases two of which, "a book" and "to him", are obligatory and one, "in the park", is optional. This grammatical arrangement also applies to Persian language with the difference that in Persian, noun phrases with specific syntactic functions can be reordered in the sentence without any impairment to grammatical or semantic structure. For instance, the above example can be cast into any of the following forms:

"Man ketabi be oodar park dadeham." (I a book to him in the park have given.)

"Ketabi man be oo dar park dadeham." (A book I to him in the park have given.)

$\mathbf{1 2 3 0} \mid \mathrm{P}$ a g e

July 2017

w w w. cir world. com 
"Be oo man ketabi dar park dadeham." (To him I a book in the park have given.)

"Dar park man be oo ketabi dadeham." (In the park I to him a book have given.)

"Dar park man ketabi be oo dadeham." (In the park I a book to him have given.)

"Dadeham man ketabi be oo dar park." (Have given I a book to him in the park.)

Some noun phrases can even be omitted without tampering the meaning or impairing the grammatical structure of the sentence. Like in "Ketabi ra be oo dadeham." (A book to him I have given.) But in English, only the syntactic position of some noun phrases can be reordered and any noun phrase put in the subject position cannot be omitted. As in "I have given to him a book in the park/ I have given in the park a book to him."

The Persian poets frequently use this feature in their works. That is, they build a collection of devices to create a sense of alienation in their poetic utterance by reordering the grammatical structure of their sentences. By using these poetic devices they, besides conveying the meaning, attempt to create novel sentences for their addressees. For example, they sometimes reorder the verb position. Like in: "Bordamtan-e porazatash-e khodra /Dar omq-e abe-e shoorbiandazam" (Rahmani, 2014: 112)

They also sometimes reorder the position of all the elements of a sentence. For instance:

"Ba jonbeshastpeikar-e oogarm-e yekjedal /Bbastehastnaqsh bar tan-e labhayash /Tasvir-e yeksoal'3 (Sepehri, 1985: 50)

In English, the main verb always follows the subject, so its position cannot be reordered easily. As seen in the following segment, all verbs; i.e. "write", "twisted", "trod", and "rise" are appeared after the subjects of "l" and "you":

"You may write me down in history /With your bitter, twisted lies, /You may trod me in the very dirt /But still, like dust, I'll rise" (Maya Angelou)

In any language, conveying a message without using the acceptable ways is meant to escape from linguistic norms. As a result, the poets to create more literary language employ deviation method. In other words, to make more impression on their addressees, they foreground their utterances by using defamiliarization techniques in lexical items and grammar rules of their poetry. According to Shafiee Kadkani, "The most difficult type of defamiliarization occurs in syntactic domain because in any language, the syntactic possibilities and alternatives are somehow assumed to be among the most limited ones. However, from another point of view, the very syntactic domain enjoys the most linguistic variation. For example, in Abd-al-Qaher Jorjani's view, rhetoric and effectiveness exclusively belong to the realm of syntactic structures of language. Therefore, he calls it "elm-e Maani-ol-Nahv" (syntactic knowledge) that is meant the poet or writer's knowledge about syntactic usages as well as his/her awareness of the possible functions that any linguistic structure can carry out" (Shafiee Kadkani,2007: 30-31). Therefore, if the noun and/or verb phrases are misplaced or omitted from the sentence, it will result in a more literary structure. The Persian contemporary poets frequently take advantage of this technique to highlight their poetry and create a poetic effect. For example:

"Dar daman-e sokoot-e gham-afzayat /Andooh-e khoftehmidahadazaram"4 (Farrokhzaad, 1973: 52)

In the segment above, there are two "noun phrases" that none of them has been put in its main position. There is also a "verb phrase" that even, contrary to the Persian grammatical arrangement;its head is placed before its dependent.

In Persian language, the syntactic function of noun phrases, in addition to their position in the sentence, is designated by some linguistic devices such as object marker and preposition. The object marker in Persian is the suffix“-ra”. Like in:

"Dar kenar-e cheshmehay-e Salsabil-e too /Ma nemikhahimaankhab-e talaeera" (Farrokhzaad, 1969: 34)

Naturally, sometimes the poet omits the marker "-ra" to increase the impression of his/her innovative utterance. As in:

"To ham-e raz-e jahanrikhtehdarchashm-e siyahat /Man ham-e mahv-e tamashayenegahaf" (Moshiri, 2012: 93)

But, in English the syntactic function of object is primarily determined by a word's position in the sentence. The typical position of an object in English, as an SVO language, is after the verb. Like in:

"Winds stampeding the fields under the window /Floundering black astride and blinding wet" (Ted Hughes)

Both in Persian and English languages the prepositional phrase is placed in the "complement" position. However, "each preposition expresses a particular concept and grammatical relations" (Meshkatod-Dini, 2001: 200). There is a difference between the two languages regarding the prepositional phrase arrangements. That is to say, sometimes in Persian the existence of a preposition in a "noun phrase" is quite necessary. Therefore, the omission of the appeared "complement" is not possible. This kind of complement is called "verb complement" which its preposition is followed by a verb. For example:

"Fareghazafsane-ye Jamshid o Jam /Mandeh-am darcharchoob-e nam-e khish

Gar be damibayadoftadankonoon /Man be hekmatbargozidam dam-e khish"7 (Atashi, 2012: 55)

In the segment above, the preposition "dar" has come with the verb "mandeh-am". However, sometimes the existence of a preposition in a "noun phrase" located in the "complement" position is not a necessary part of the sentence. So the appeared "complement" can be omitted. This kind of complement is called "adverbial complement".

"Bi to mahtabshabibazazankoochegozashtam /Hame tan chashshodamdideh be donbal-e to gashtam"8 (Moshiri, 2012: 92)

1231 | P a g e

July 2017

w w w . cir world. co m 
As seen above, the Persian preposition "dar" has been omitted from the noun phrase "mahtab shabr" (a moonlight night). But the complement structure in English language is not similar to Persian. So in English, the prepositions of a noun phrase functioned as the "complement" certainly must be included in the sentence. Like in "You've made your mark like bird tracks in the sand /Now make the air in your lungs your livelihood" (Ros Barber)

The necessity for the existence or non-existence of a preposition in a noun phrase functioning as a complement or rearrangement or omission, all or part, of a noun phrase combined with a proposition, without any impairment to grammatical or semantic structure of the sentence, has provided a possibility for Persian language poets to create poetic and innovative sentences andmake theirutterance sound more impressive and lasting.

"Doshmannahoftehkineh be peyman-e ashti/Aloodehzahrbashekar-e boosehay-e mehr"9 (Atashi, 2012: 72)

In the above segment, the two phrases "be peyman-e ashti" (in a reconciliation pact) and "ba shekar-e boosehay-e mehr" (with the sugar of kind kisses) are noun phrases combined with propositions that function as complements and have not been put in their main positions. But, in English a noun phrase combined with a proposition does not enjoy the aforementioned capabilities of Persian language.

"The blue jay scuffling in the bushes follows /Some hidden purpose and the gush of birds /That spurts across the field the wheeling swallow" (Thom Gunn)

Another point to ponder is that in Persian language, sometimes noun phrases functioning as "complements" are associated with object market "ra" rather than being combined with an appropriate proposition:

"Agar omri be zendanamkeshidi /Rahakon diagram in yeknafasra"10 (Farrokhzad, 1973: 35)

In the segment above the phrase "in yek nafas" (this last breath), because of combining with object market "ra", performs the formal function of object, while the original phrase is "baraye in yek nafas" (for this last breath) that carries out the syntactic function of "complement" in the sentence. Or in the following segment:

"Doroodeyvapasinsobheysaharbedrood /KebaArashtoura in akharindidarkhahadbood"11 (Kasra'i, 2014: 64)

"Tou" (you) has come with the object marker "ra", while it must be associated with the preposition "baraye" (for) to be exactly characterized its syntactic function in the sentence. But the poet, by using the object marker "ra" instead of the preposition "baraye", has made his words more emphatic.

In Persian language, prepositions can also be compound like "bar rooye" (on), "dar rooye" (on), "be sooye" (towards). Sometimes, a part of the preposition of a noun phrase functioningas the "complement" is omitted. In the following segment, the phrase "rooye sahneh" (on the stage) has a compound preposition and should be written "darrooye sahneh" (on the stage), but one of its prepositions, i.e. "dar" has been dropped:

"Jayatemshabdartamashayampedarkhali /Koodakihabazrooyesahnehmiayand"12 (2000: 40)

Persian poets even rearrange the internal orders of the noun and verb phrases to achieve greater impact on their audience. In the following example:

"Dar-e meykhanehraqoflibezantarsamkevelgardi /Zedard-e atashinzakhmamkhabargardad"13 (Rahmani, 2014: 41)

The phrase "atashinzakhmam"(fiery scar of mine) is a rearranged noun phrase that its original form is "zakhm-e atashinam" (my fiery scar) and its head is "zakhm" (scar). Therefore, after the rearrangement, the head phrase is used with possessive personal pronoun (subordinate 3) and the adjective "atashin" (fiery), as subordinate 2, is placed before the head. They may also embed a noun phrase within another. In the following example:

"Bar darreyeamiqkepastooyejangalast /Lakhtisokootchirehshavadsard-o vatarsnak"14 (Akhavan Sales, 1991: 167)

The verb phrase "chirehshavad" (prevails) is placed within the noun phrase "sokoot-e sard-o tarsnak" (cold and fearful silence). Or in the segment below:

"Inak in pakizeh- tan morghakrahavard-e manast /Peikaridaradchorouhampak-o chon mooyamsepid"15 (Akhavan Sales, 1991: 19)

The poet has disarranged all parts of the noun phrase. Namely, the noun phrase "in pakizeh- tan morghak" is an intermixed one that its head (morghak)is placed at the end.

One of the differences between Persian and English noun phrases is that in English, nouns and adjectives can take a complement. However, such complements never appear as solo noun phrases in surface structure and have to take a transformation by adding "of" before them like in:

The picture the dog $\rightarrow$ The picture of the dog (Cook and Newson, 2011: 122).

In Persian, a noun phrase can also take a complement. The complement joins the head noun with a kasrah morpheme (vowel point) like in "zan- $\underline{e}$ hamsayeh" (the neighbor woman) or "ketab-e Fars" (Farsi book).Sometimes, the contemporary Persian poets change the position of head and complement in a noun phrase. In the following segment:

"Ehsasmikonam /darchashm-e man /be abshor-e ashk-e sorkhgoon /khorshid-e beghoroobsoroodikeshadnafas" ${ }^{16}$ (Hoqooqi, 1990: 97)

1232 | P a g e

July 2017

w w w . cir world. co m 


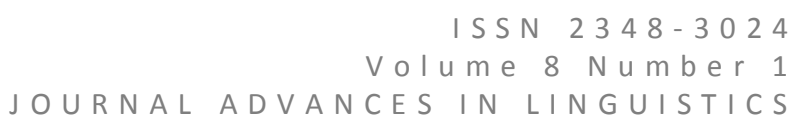

The words of the noun phrase "abshor" (flow of water), in comparison with its original order that is "shorreye-ab", are displaced.

Sometimes two noun phrases with different syntactic functions are mixed with each other. In the following example:

"Yana to ham baharbahanehshanehkhalikon /Az man- man-e in bar shaneha bar-e geraneydoost"17 (Bahmani, 2000: 182)

Each of the noun phrases "in bar-e geran" (this heavy burden) and "bar shaneha" (on shoulders) have a particular syntactic function in the sentence. The first and second phrases have an objective and complementary functions respectively. However, the poet has mixed them together.

Sometimes the poet interchanges the position of the dependents before the head of a noun phrase with those of after it. In the following segment:

"Yekshab be khab-e naz agar miraft /Ansooyepelk-e khasteyekhodmidid /Fath-e telesmhahamehbaoost"18 (Bahmani, 2000: 14)

The word "hameh" (all) is leading subordinate 1 for noun phrase "fath-e telesmha" (conquering the talismans) which is displaced in the phrase. There are segments among contemporary Persian poems which are noticeable for the structure of noun phrases. For instance, in the following segment:

"Yaran-e nashenakhteam /Chon akhtaran-e sookhteh /Chandanbekhak-e tirehforoorikhtandsard" ${ }^{19}$ (Hoqooqi, 1990: 87)

The compound verb "foroorikhtand" (fell down) is placed exactly in the middle of the noun phrase "khak-e tireye sard" (dark cold ground). Obviously, this noun phrase is a compound one, i.e. it has two heads. The first head, "khak" (ground), is placed in the noun phrase "khak-e tireh" (dark ground) and the second head, "tireh" (dark), is located in the noun phrase "tireye sard" (dark cold) which is the following subordinate for the first phrase.

In Persian, a number of noun phrases consist of only one noun and one adjective, which grammatically are termed as "descriptive phrases" like "beautiful flower" or "old man". Poets sometimes change the word order of these phrases, without noticing the basic structure of them, in order to spotlight their poetry and leave a lasting effect on the addressees. In following segment, the word order of the noun phrase "khomarin pelkha" (sleepy eyelids) has been displaced. As a result the head phrase, "pelkha" (eyelids), has been located after its following subordinate that is "khomarin" (sleepy):

"Jorekhabi /Bekhomarinpelkhamishodgahinooshand"20 (Bahmani, 2000: 16)

Verbs in Persian can be classified into two major groups: "simple" and "compound". Compound verbs consist of at least two components. "The first component that is not inflectional is made up a noun, adjective, or adverb and the second one that is inflectional is made up a verb. These components are respectively named as hamrah (companion) and hamkard (compound)" (Tabatabaee, 2006: 26). In a verb phrase, "hamkard" (compound) is the same as the head. For instance, in phrase "moshahedeh kardand" (They observed), the word "kardand" is the head and also "hamkard" (compound). Usually the arrangement of verb phrases in predicative sentences do not change. However, in contemporary Persian poems, sometimes the poet change this arrangement like in the following segment:

"Lik an lahzehkenakhonhayedast-e ashenayeraz /Raft ta bar takhtehsangikar-e kandanrakonadaghaz"21 (Sepehri, 1985: 61)

Verbs in Persian are used in three tenses of past, present, and future. But the form of a verb changes for each tense. For instance, the following rule has to be followed for a verb conjugated in the future tense. The present stem of "khah" (want) together with the past stem of any verb Constitute the future tense of that verb. The present stem of "khah" (want) in this verbal combination indicates the future tense of the verb. It is worth to point out that the verbal indicators in this combination are accompanied with the verb marker "khah" (want) like in khaham raft (I will go) or khahand goft (they will say). Even the negation prefix is attached to the verb marker "khah" (want) like in nakhahim did (we will not see). Some contemporary Persian poets have changed arrangement of words in such verb forms:

"Azzereyejametan agar beshkoofid/Bad-e divaneh/Yal-e boland-e asb-e tamannara /Ashoftehkardkhahad"22 (Shamlou, 1985: 10)

Even simple verbs are used in poems with this device:

"Mowjharaparehkhahadkard/Verd-e bozdelankhandkhahad bar khoroosh-e yavehjooshat"23 (Atashi, 2012: 113)

Also, sometimes the negation marker is attached to the head of a verb:

"Digarnaroostkhahadazastin-e man /An dokhtarnpeikareshanmadehahoovan"24 (Atashi, 2012: 73)

None of the above mentioned alterations in the arrangement of words used for noun and verb phrases in Persian are applicable in English. The English poet cannot rearrange the components of noun or verb phrases in his/her poetic sentences or attach an affix to any word against the grammatical rules of English. In the below segment the poet, following the verb phrase "have calmed", has omitted the auxiliary verb "have" from the verb phrase "brought" in order to create poetic and innovative sentences:

"Once a great love cut my life in two /The first part goes on twisting /At some other place like a snake cut in two./The passing years have calmed me/And brought healing to my heart and rest to my eyes." (Yehuda Amichai)

1233 | P a g e

July 2017

w w w. cirworld.com 


\section{CONCLUSION}

To create poetic works, the contemporary Persian and Englishpoets use various devices which are usually obtained based on the essence of language. For instance, English poets in creating genuine and impressive poems cannot reorder the internal orders of noun or verb phrases in their poetry. So they create their poetic utterancesby generating internal melody and using the meter.While the internal structure and language capacity in Persian enjoys more devices. The poets, who write their poetry in Persian, can create impressive poetic verses by reordering the internal order of noun or verb phrases and uncommon orders of them, deleting a part, or substituting a word for another. That is, they can escape from prevailing norms of language by generating formal or internal changes in noun or verb phrases and by foregrounding their utterances, create genuine poetic verses. It is worthy to note that it is not possible to distinguish the poetry style of each of the poets simply according to the special types of noun or verb phrases they have used; however, it is possible to differentiate these types, characterize the internal orders of each, and enumerate their differential aspects.

\section{End-Note}

1-Breathless became the blackness in the morning mouth / The wind fell feathers on the open plain of Alborz Mountains' skirt

2-Took I the body full of thirst of mine /In the depth of saltwater to throw

3-Against motion is its body busy in a battle /Has been imprinted on the flesh of its lips /The image of a question

4-On the lap of your saddening silence /The dormant grief bothers me

5- Beside Salsabil fountains of yours /We do not want that golden dream

6- You all the secrets of the worldbeing carried in the black eyes of yours /I all being wrapped in watching your eyes

7- Regardless of the legend of Jamshid and Cup /I have been left in the frame of my own name /If it is supposed to fall into a trap now /I in my wisdom chose my own trap

8- Without you on a moonlight night, once again through the same alley I passed /My body, all an eye gazing in search of you

9- The enemy has wrapped the hatred in a reconciliation pact /Smeared poison with the sugar of kind kisses

10- If imprisoned me all my life /Let me alone this last breath

11- Hello there the last morning O'dawn goodbye /That to you it will be the last meeting with Arash

12- Missing you tonight watching me dad /The childhood (memories) are coming back to the stage

13- Lock the tavern's door I fear a vagrant /Might figure out about the pain of my fiery scar

14- In the deep valley that is the forest's closet/For a while, silence prevails cold and fearful

15- Now this chaste little bird is my souvenir /t has a body clean like my soul and white like my hair

16- I feel /In my eye /Amidst the flow of blood-red tears /Down-less sun gasps a hymn

17- Or not you too evade using any excuse /Me- me too heavy burden on shoulders, oh you friend

18- One night if he sank into a relaxing sleep /Beyond his tired eyelid he would see /Conquering the talismans all is on him

19- My unknown comrades/Like burnt starsSo many fell on the dark ground cold

20- A sip of sleep /Could be given now and then to sleepy eyelids

21- But the time that the nails of the familiar hand of mystery /Went to start digging into a rock

22- If you blossom out of your garment's armor /Wild wind /The long mane of the horse of desire /Will disturb

23- Would tear the waves /Would sing cowards' incantation on your nonsense roaring

24- Will never grow in my hand /Those girls with gazelles' bodies 


\section{ACKNOWLEDGMENTS}

The author gratefully acknowledges financial and other support for this research, provided by the Islamic Azad University, Eslamshahr Branch, Tehran ,Iran.

\section{REFERENCES}

1. Akhavan Sales, M.1991. Winter, Tehran: Morvarid.

2. Atashi, M. 2012. Selected Poems, Tehran: Morvarid.

3. Bahmani, M.A. 2000. The Poet is Worth Hearing: Selected Poems, Tehran: Darinoosh.

4. Cook,V.J.and Newson M. 2011. Chomsky's Universal Grammar: An Introduction, trans. Ebrahim Chegeni, Tehran: Rahnama.

5. Farrokhzaad, F. 1969. Rebellion, Tehran: Amirkabir.

6. Farrokhzaad, F. 1973. The Captive, Tehran: Amirkabir.

7. Hoqooqi, M. 1990.Poem of Our Times: Ahmad Shamlou, Tehran: Negah.

8. Kasra'i, S. 2014. Selected Poems, Tehran: Morvarid.

9. Meshkatod-Dini, M. 2001. Introduction to Persian Transformational Syntax, Mashhad: Ferdowsi University.

10. Moshiri, F. 2012. Root in Soil: Selected Poems, Tehran: Morvarid.

11. NatelKhanlari, P. 1988. Persian Grammar, Tehran: Toos.

12. Nematzadeh, S. 1997. "Head Parameter and Indexing: A Comparison between Persian and English Noun Phrase", Library and Information Science, Vol. 12, No. 1.

13. Qorbanpour, A. 2015. "Head Position Parameter in Persian: An Optimality-Theoretic Approach", Language Science Journal (Elm-e-Zaban), Vol. 2, No. 3.

14. Rahmani, N. 2014. Selected Poems, Tehran: Morvarid.

15. Rezaee, H. 2011. "Head Position in Persian: From a Diachronic Typology Viewpoint”, Journal of Researches in Linguistics, Vol. 3, No. 5.

16. Sepehri, S. 1985. The Eight Books, Tehran: Tahoori.

17. ShafieeKadkani, M.R. 2007. The Musical Aspect of Poetry, Tehran: Agah.

18. Shamlou, A. 1985. The Mirror Garden, Tehran: Morvarid.

19. Tabatabaee, S.A. 2006. "Compound Verb in Persian". Academy of the Persian Language and Literature Newsletter (Nâmeh-ye Farhangestân), No. 26.

20. VahidianKamyar, T. 2008. Persian Grammar (1), Tehran: Samt.

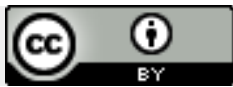

This work is licensed under a Creative Commons Attribution 4.0 International License.

DOI : 10.24297/jal.v8i1.6216 
